\title{
Toward the development of a multi parametric system for a short-term assessment of the seismic hazard in Italy
}

\author{
Nicola Genzano ${ }^{1}$, Carolina Filizzola ${ }^{2}$, Mariano Lisi $^{2}$, Nicola Pergola ${ }^{2}$, Valerio Tramutoli ${ }^{1}$ \\ (1) School of Engineering, University of Basilicata, Potenza, Italy \\ (2) Institute of Methodologies for Environmental Analysis of the National Research Council, Tito Scalo (PZ), Italy
}

Article history: received October 23, 2019; accepted January 2, 2020

\begin{abstract}
With the aim to develop a multi-parametric system devote to improving our present capability to assess seismic hazard particularly in the short-medium term, the preliminary step is to identify those parameters that have demonstrated their non-casual relation with earthquake occurrences and whose anomalous variations can be associated to the complex seismic process. Since '80s, fluctuations of Earth's thermally emitted radiation, measured by satellite sensors in the Thermal InfraRed (TIR) spectral region, have been reported by several authors in some connection with the occurrence of earthquakes; they can be considered as one of the possible parameters to include within a multi-parametric system.

In this paper, the Robust Satellite Techniques (RST) approach has been exploited to highlight Significant Sequences of TIR Anomalies (SSTAs) possibly related to seismic events happened in Italy in the period June 2004 - December 2014. In particular, we evaluated the level of correlation between occurrence of earthquakes with $\mathrm{M} \geq 4$ and RST-based TIR anomalies using two different spatial resolutions of MSG-SEVIRI (Meteosat Second Generation -Spinning Enhanced Visible and Infrared Imager) images.

Results of the two RST analyses show that the $82 \%$ of the identified SSTAs does not disappear when downscaled spatial resolution SEVIRI TIR records were used. For both analyses, more than $60 \%$ of SSTAs is apparently in connection with the occurrence of $M \geq 4$ earthquakes; more than the $80 \%$ of them has tendency to anticipate the occurrence of earthquakes. Although about the $40 \%$ of SSTAs is not apparently related to documented seismic activity (false positives), results of random tests (i.e. Molchan's error diagrams) indicate a non-casual correlation between SSTAs and earthquake occurrences.

These results confirm that the parameter "RST-based satellite TIR anomalies" is one of the possible candidates to be included in a multi-parametric system for time-Dependent Assessment of Seismic Hazard (t-DASH).
\end{abstract}

Keywords: Satellite thermal anomalies, Earthquakes, Correlation analysis, Seismic hazard assessment, Multi-parametric system. 


\section{Nicola Genzano et al.}

\section{Introduction}

The occurrence of even destructive earthquakes in areas that until then were not considered at high seismic hazard, on the basis of probabilistic maps, highlighted the weakness of approaches such as the Probabilistic Seismic Hazard Analysis [PSHA; Cornell, 1968], widely used for almost 50 years but never validated by objective testing [Mulargia et al., 2017]. Events of Sumatra (26 December 2004, Mw=9.1), Kashmir (8 October 2005, Mw=7.6), Wenchuan (12 May 2008, Mw=7.9), Haiti (12 January 2010, Mw=7.0), and Tohoku (11 March 2011, Mw=9.0) are only the most striking examples of understated seismic hazard [Geller, 2011; Kossobokov and Nekrasova, 2012; Stein et al., 2012; Kagan and Jackson, 2013] which caused heavy human and economic losses.

The increasing awareness that seismic hazard cannot be assessed exclusively through such traditional approaches has progressively led to exploring new ways. Integration of multi-parametric observations seems to be the direction that scientific community is recently taking in the attempt to improve our present capability to assess seismic hazard particularly in the short-medium term. Building up a system based on continuously updated observations (i.e. timedependent), provided that they are adequately selected and analysed, may represent a hopeful research line to actually exploit accumulated knowledge and improve quality of seismic hazard. Isolated attempts of multi-parametric approaches were done during specific conferences (e.g. the 2018 Workshop on Electro-Magnetic Studies of Earthquakes and Volcanoes; EMSEV 2018 website, 2018) or within the framework of international research projects such as EU-FP7 PRE-EARTHQUAKES (Pre-earthquakes project website, 2019) and iSTEP (integrated Search for Taiwan Earthquake Precursors [Tsai et al., 2006]).

Increased reliability and precision can be expected from multi-parametric t-DASH (time-Dependent Assessment of Seismic Hazard [Tramutoli et al., 2014]) systems. In fact, considering just the intersection of space-time volumes individually alerted by each parameter, a significant reduction of both, the (combined) probability of false alarms and alerted space-time volumes can be achieved. Seismic hazard levels associated to specific space-time volumes can be then systematically updated on the basis of the specific alerted space-time windows and predictive capabilities of the considered parameters. However, the selection of suitable (chemical, physical, biological ...) parameters to be integrated within such a t-DASH system is not a trivial task.

In principle, a candidate parameter suitable for integration in a t-DASH system should:

a) be selected on the basis of experimental observations and/or convincing physical models (e.g. Scholz et al., [1973]; Tronin, [1996]; Freud, [2007a]; Pulinets and Ouzounov, [2011]; Huang, [2011b]; Tramutoli et al., [2013]) that could justify their appearance within the complex process of an earthquake preparation phase;

b) be measurable with sufficient space-time continuity; in this context, satellite-based observations may have a great potential because they guarantee information over large areas (up to a global scale) in a quite continuous way.

c) exhibit space-time transients (potentially related to EQs) identifiable through clear, scientifically founded and repeatable, data analysis techniques. In fact, even if a huge amount of scientific papers reports the appearance of variations of geophysical parameters (e.g. Tronin, [2006] and reference therein; Cicerone et al., [2009]) in some relation with the occurrence of seismic events, used methodologies and the definition itself of "anomaly" concept are not always clearly stated.

d) Show a non-occasional relation between space-time transients and earthquake occurrence, which should be preliminarily established by specific long-term (plurennial) correlation analyses. An actual correlation with earthquake characteristics (e.g. time, position, magnitude) can be appropriately evaluated only if long-term correlation analyses are performed. Only from such analyses it will be possible to quantitatively characterize the predictive capabilities (in terms of successful forecasts, false positive rates and/or missed events) of each parameter with reference to specific regions, alerted space-time volumes, expected earthquake magnitudes, etc. Good examples of such long-term correlation analyses are represented by studies concerning variations of the plasma frequency at the F2 peak foF2 of ionosphere during 1994-1999 [Liu et al., 2006], Ultra Low Frequency (ULF) geomagnetic signals over a 10-year period [Han et al., 2014], ionospheric ion density recorded by DEMETER satellite during more than 6 years [Li and Parrot, 2013] and, more recently, Earth's thermally emitted radiation [Eleftheriou et al., 2016].

e) Provide an appreciable improvement of the EQ forecast capability of the whole t-DASH system.

With all that in mind, in this paper we consider the Earth thermally emitted radiation, measured by satellite sensors in the Thermal InfraRed (TIR) spectral region, as a suitable candidate for a t-DASH system. Since the ' 80 s, several 
authors [Gorny et al., 1988; Qiang and Dian, 1992; Tronin ,1996; Qiang et al., 1997; Tronin et al., 2002; Ouzounov and Freud, 2004; Choudhury et al., 2006; Ma et al., 2010; Tramutoli et al., 2015a, 2018a; and reference therein] have been reporting TIR anomalous transients (hereafter "TIR anomalies") in some connection with the occurrence of earthquakes. Different physical models have been invoked to explain their appearance before and even after [Scholz et al., 1973] a seismic event. Among them, it is worth mentioning the increase of greenhouse effect due to an anomalous degassing of optically active gases such as $\mathrm{CO}_{2}$ and $\mathrm{CH}_{4}$ [Qiang et al., 1991; Tramutoli et al., 2001, 2005, 2013; Tronin, 1996; Zhang et al., 2010], the atmospheric warming after a massive radon emission (Lithosphere-AtmosphereIonosphere Coupling (LAIC) model; [Pulinets and Boyarchuk, 2004; Pulinets, 2004, 2006; Yasuoka et al., 2006; Pulinets and Ouzounov, 2011]), and the activation of positive holes in stressed rock volumes [Ouzounov and Freund, 2004; Freund, 2007a, 2007b; Freund et al., 2006, 2007; Wu and Liu, 2009; Wu et al., 2012].

A quite long list of works [see detailed reviews in Tramutoli et al., 2015a, 2018a; Jiao et al., 2018] exists where different satellite-based approaches, many of which have been object of criticism, try to highlight TIR anomalies in some relation with seismicity. These methodologies use satellite data such as those acquired by the Advanced Very High Resolution Radiometer (AVHRR) carried on the National Oceanic and Atmospheric Administration (NOAA) satellites (e.g. Tronin, [1996]), the Meteosat Visible and Infrared Imager (MVIRI) on the Meteosat First Generation (MFG) platforms [Qiang et al., 1997], the Japanese Geostationary Meteorological Satellite (GMS) [Xu et al., 2000], the Multifunctional Transport Satellite (MTSAT-1R) [Yang and Guo, 2010], the Chinese Feng Yun 2C [Zhang et al., 2010] and 2E [Xie et al., 2013], the Moderate Resolution Imaging Spectroradiometer (MODIS) aboard the Earth Observing System (EOS) [e.g. Ouzounov and Freund, 2004], and the Spinning Enhanced Visible and Infrared Imager (SEVIRI) on board the Meteosat Second Generation (MSG) satellites [e.g. Piroddi and Ranieri, 2012]

As shown in several quoted papers [e.g. Tramutoli et al., 2001, 2005, 2009, 2015b, 2018b; Filizzola et al., 2004; Di Bello et al., 2004; Corrado et al., 2005; Aliano et al., 2007, 2008a, 2008b; Genzano et al., 2007, 2009a, 2009b, 2015; Lisi et al., 2010,2015; Pergola et al., 2010; Eleftheriou et al., 2016], differently from other approaches, the RST [Tramutoli, 1998, 2005, 2007] methodology is able to isolate residual TIR variations which are potentially related to seismic events from normal TIR fluctuations due to other causes. This is done following a well-defined procedure, based on a statistical definition of what a TIR anomaly means, which has been reproduced also in independent studies [e.g. Eneva et al., 2008; Halle et al., 2008; Blacket et al., 2011; Okyay 2012; Xiong et al., 2013; Khalili et al., 2019].

The application of the RST technique to tens of earthquakes, occurred in four different continents and geo-tectonic contexts, with magnitudes ranging from 4.0 to 7.9, using both polar (NOAA-AVHRR, EOS-MODIS) and geostationary (MFG-MVIRI, MSG-SEVIRI, GOES-IMAGER, MTSAT-IMAGER) satellite data, permitted us to find correlations between TIR anomalies and seismic event occurrence, mainly selecting a space window based on the Dobrovolsky et al. [1979] distance and a time window ranging from 30 days before to 15 days after a seismic event. At the same time, such longterm correlation analyses allowed us to highlight the appearance of spurious TIR anomalies, for example, in case of quite rare events which are able to increase (for more than 1 day) measured TIR signal due to an increase of surface temperature (e.g. extended forest fires) or emissivity (e.g. very large floods). However, it is expected that large-scale phenomena (e.g. Earth degassing) continue to produce TIR anomalies also in large size pixels, while small-scale events (e.g. forest fires) can give a decreasing contribution to the TIR signal as the pixel size increases.

In this paper, we evaluate the level of correlation between occurrence of earthquakes with $M \geq 4$ and RST-based TIR anomalies using two different spatial resolutions of SEVIRI images. In particular, the same TIR SEVIRI time series (from June 2004 to December 2014) is analysed at full SEVIRI pixel resolution as well as at a downscaled spatial resolution ( $3 \times 3$ pixel box). Results will be compared and random tests (Molchan diagram) will be performed in both cases to assess the lack of randomness in the appearance of RST-based TIR anomalies.

\section{Data analysis}

\subsection{RST methodology and RETIRA index}

The method proposed by Tramutoli et al. [2001], [2005] , called RST (Robust Satellite Techniques) is mostly based on the general approach named RAT (Robust AVHRR Technique; Tramutoli, [1998]). Being the RAT methodology exclusively based on satellite data at hand (no ancillary data are requested), it is intrinsically exportable on different 


\section{Nicola Genzano et al.}

satellite packages, reason why the original name RAT was changed in the more general RST [Tramutoli, 2005; 2007].

The RST approach is devoted to isolating possible anomalies from those signal variations, that are related to known, but also unknown, natural and/or observational factors [e.g. surface spectral emissivity, temporal variations of satellite view angle, etc.; see Tramutoli et al., 2005], which can be responsible for "false alarm" proliferation. It is based on a multi-temporal analysis of a historical dataset of satellite observations, which were acquired in similar observational conditions (e.g. same month of the year, same hour of the day, same sensor, etc.), devoted to characterizing the measured signal (in terms of its expected value and variation range) for each pixel of the satellite image to be processed. In this way, space-time anomalies can be identified by comparing the measured signal, in the geographical position $\mathbf{r}$ at time $t^{\prime}$, with a preliminarily computed signal behavior.

In order to identify abnormal fluctuations of the measured signal (i.e. anomalies), the general index ALICE (Absolutely Llocal Index of Change of the Environment) ${ }^{1}$ has been proposed for the first time by Tramutoli [1998] and it is reported below:

$$
\bigotimes_{V}\left(\boldsymbol{r}, t^{\prime}\right)=\frac{\mathrm{V}\left(\boldsymbol{r}, t^{\prime}\right)-\mu_{V}(\boldsymbol{r})}{\sigma_{V}(\boldsymbol{r})}
$$

Where $V\left(\boldsymbol{r}, t^{\prime}\right)$ is the value of a variable $V$ at location $\boldsymbol{r}$, and at acquisition time $t^{\prime}, \mu_{V}(\boldsymbol{r})$ and $\sigma_{V}(\boldsymbol{r})$ are respectively the expected value (usually the time average) and the standard deviation of $V\left(\boldsymbol{r}, t^{\prime}\right)$ computed on cloud-free records belonging to the selected dataset.

By this way, the ALICE index provides a statistically well-based definition of local signal anomalies. Moreover, the intensity of anomalies can be evaluated in terms of Signal to Noise ratio (S/N) because $\mathrm{V}\left(\boldsymbol{r}, \mathrm{t}^{\prime}\right)-\mu_{V}(\boldsymbol{r})$ represents the Signal $(S)$ to be investigated for its possible relation with studied phenomena and $\sigma_{V}(\boldsymbol{r})$ represents its natural and observational Noise $(N)$, as historically observed at the same site in similar observational conditions.

In order to better characterize the analyzed signal a historical, homogeneous (same platform, period of the day, period of the year, etc.) and long-term dataset of satellite images should be constructed. In fact, selecting satellite images acquired in the same period of the year and in the same hour of the day (e.g. midnight), it is expected a reduction of the signal variability linked to the daily (diurnal variation of the temperature) and annual (seasonal variation of the temperature and emissivity, which is mainly related to the different vegetations coverage) solar cycle. Moreover, in the case of studies on Earth's thermally emitted radiation, using only nighttime images, which are less influenced by effects related to soil-air temperature differences, normally higher during other hours of the day, and less sensitive to local solar exposition, further elements of variability of the signal (independent of the seismicity) can been reduced.

In order to identify possible TIR anomalies associated to seismic activity, the RETIRA (Robust Estimator of TIR Anomalies) index has been used. The RETIRA index belongs to the most general class of the ALICE indexes, it has been introduced for the first time by Filizzola et al. [2004] and subsequently has been always applied in all RST applications [Tramutoli et al. 2005, 2015b, 2018b; Corrado et al., 2005; Aliano et al., 2007, 2008a, 2008b; Genzano et al., 2007, 2009a, 2009b, 2015; Lisi et al., 2010; Pergola et al., 2010; Eleftheriou et al., 2016] devoted to the thermal monitoring of seismic areas. It can be computed as follows:

$$
\bigotimes_{\Delta T}\left(\boldsymbol{r}, t^{\prime}\right)=\frac{\left[\Delta T\left(\boldsymbol{r}, t^{\prime}\right)-\mu_{\Delta T}(\boldsymbol{r})\right]}{\sigma_{\Delta T}(\boldsymbol{r})}
$$

where:

- $\boldsymbol{r} \equiv(\mathrm{x}, \mathrm{y})$ represents location coordinates on a satellite image;

- $t$ ' is the time of acquisition of the satellite image at hand, with $t \in \tau$ where $\tau$ defines the homogeneous domain of satellite imagery collected in the same time-slot (hour) of the day and period (month) of the year;

- $\Delta T\left(\boldsymbol{r}, t^{\prime}\right)=T\left(\boldsymbol{r}, t^{\prime}\right)-<T\left(t^{\prime}\right)>$ is the difference between the current $\left(t=t^{\prime}\right)$ TIR signal $T\left(\boldsymbol{r}, t^{\prime}\right)$ measured at location $\boldsymbol{r}$,

\footnotetext{
${ }^{1}$ Since Tramutoli [1998] the double $l$ is used to make reference not only to a specific place $\boldsymbol{r}$ but also to a specific time $t^{\prime}$.
} 
and its spatial average $\left\langle T\left(t^{\prime}\right)\right\rangle$, computed in place on the image at hand, discarding cloudy pixels and considering only sea pixels, if $\boldsymbol{r}$ is located on the sea, only land pixels, if $\boldsymbol{r}$ is located over the land;

- $\mu_{\Delta T}(\boldsymbol{r})$ and $\sigma_{\Delta T}(\boldsymbol{r})$ are the time average and standard deviation values of $\Delta T(\boldsymbol{r}, t)$, at location $\boldsymbol{r}$, computed on cloud-free satellite records belonging to the selected homogeneous dataset $\left(t^{\prime} \in \tau\right)$.

The choice of such a differential variable $\Delta T\left(\boldsymbol{r}, t^{\prime}\right)$ instead of $T\left(\boldsymbol{r}, t^{\prime}\right)$ is expected to reduce possible contributions (e.g. occasional warming) due to day-to-day and/or year-to-year climatological changes and/or season time-drifts.

As proposed by Eleftheriou et al., [2016], a further reduction of signal variability due to particular meteorological conditions, such as the extensive cloudiness and the presence of an asymmetrical distribution of clouds within the analyzed scene, could be achieved selecting only the satellite images that are not affected by these conditions. In this study, the same criteria adopted in the study of Eleftheriou et al., [2016] have been taken in account. Briefly, land (or sea) portions of the TIR images that are excessively covered by cloud coverage (i.e. $\geq 80 \%$ of the total land/sea pixels) or affected by the cold spatial average effect [Aliano et al., 2008a; Genzano et al., 2009a] have been removed from the datasets construction, and consequently excluded from the computation of the RST reference fields (i.e. time average and standard deviation).

Land (or sea) TIR portions possibly affected by the cold spatial average effect are identified on the basis of the following expression $T\left(t^{\prime}\right) \leq \mu_{T}-2 \sigma_{T}$ (where $T\left(t^{\prime}\right)$ is the TIR spatial average computed only on cloud-free pixels of the scene acquired at time $t^{\prime}$ and belonging to the same land/sea class, $\mu_{T}$ and $\sigma_{T}$ are respectively the temporal average and standard deviation of $T\left(t^{\prime}\right)$, which are computed using all TIR images of the homogeneous dataset.

In this work, with the aim to reduce the proliferation of TIR anomalies due to sporadic and localized events (for example due to fires or to industrial accidents), and concurrently trying to preserve and emphasize TIR anomalies with an appreciable spatial extension, such as TIR anomalies possibly related to seismic activities, a new index called RETIRA $A_{\text {box }}$ has been introduced.

For each image, which represents the differential variable $\Delta T\left(\boldsymbol{r}, t^{\prime}\right)$, a spatial filter has been applied. Taking in account the schematic representation of Figure 1, every three pixels starting from the pixel at position row R2 and line L2, the spatial mean value has been computed only if 5 out of 9 pixels within a region of $3 \times 3$ pixels centered on the considered pixel were not affected by clouds. As a result, a downgrade of the image spatial resolution has been

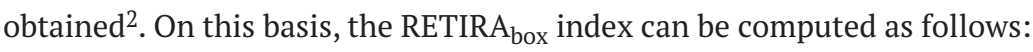

$$
\otimes_{\Delta T b o x}\left(\boldsymbol{r}, t^{\prime}\right)=\frac{\left[\Delta T_{b o x}\left(\boldsymbol{r}, t^{\prime}\right)-\mu_{\Delta T b o x}(\boldsymbol{r})\right]}{\sigma_{\Delta T b o x}(\boldsymbol{r})}
$$

where:

- $\Delta T_{b o x}\left(\boldsymbol{r}, t^{\prime}\right)$ is the spatial average of $\Delta T\left(\boldsymbol{r}, t^{\prime}\right)$ within a region of $3 \times 3$ pixels centered at location $\boldsymbol{r}$. It is computed only if 5 out of 9 pixels are clear or not close to clouds;

- $\mu_{\Delta T b o x}(\boldsymbol{r})$ is the time average value of $\Delta T_{b o x}\left(\boldsymbol{r}, t^{\prime}\right)$ at the location $\boldsymbol{r}$ computed on cloud-free records belonging to the selected data set $\left(t^{\prime} \in \tau\right)$;

- $\sigma_{\Delta T b o x}(\boldsymbol{r})$ is the standard deviation value of $\Delta T_{b o x}\left(\boldsymbol{r}, t^{\prime}\right)$ at the location $\boldsymbol{r}$ computed on cloud-free records belonging to the selected data set $\left(t^{\prime} \in \tau\right)$.

Note that only cloud-free radiances have been taken in account in the RST elaborations. So, cloudy pixels, which have been identified by OCA (One channel Cloudy radiance detection Approach; Cuomo et al., [2004], and the first neighboring pixels around them, which can be partially affected by clouds (edge clouds) which are not identified by the cloud detection analysis, have been excluded.

2 The pixel size of SEVIRI image over Italian region is averagely 3.5 (longitude) x 4.5 (latitude) $\mathrm{km}^{2}$. After the application of the spatial filter the size of new images is $\sim 10.5 \times 13.5 \mathrm{~km}^{2}$. 


\section{Nicola Genzano et al.}

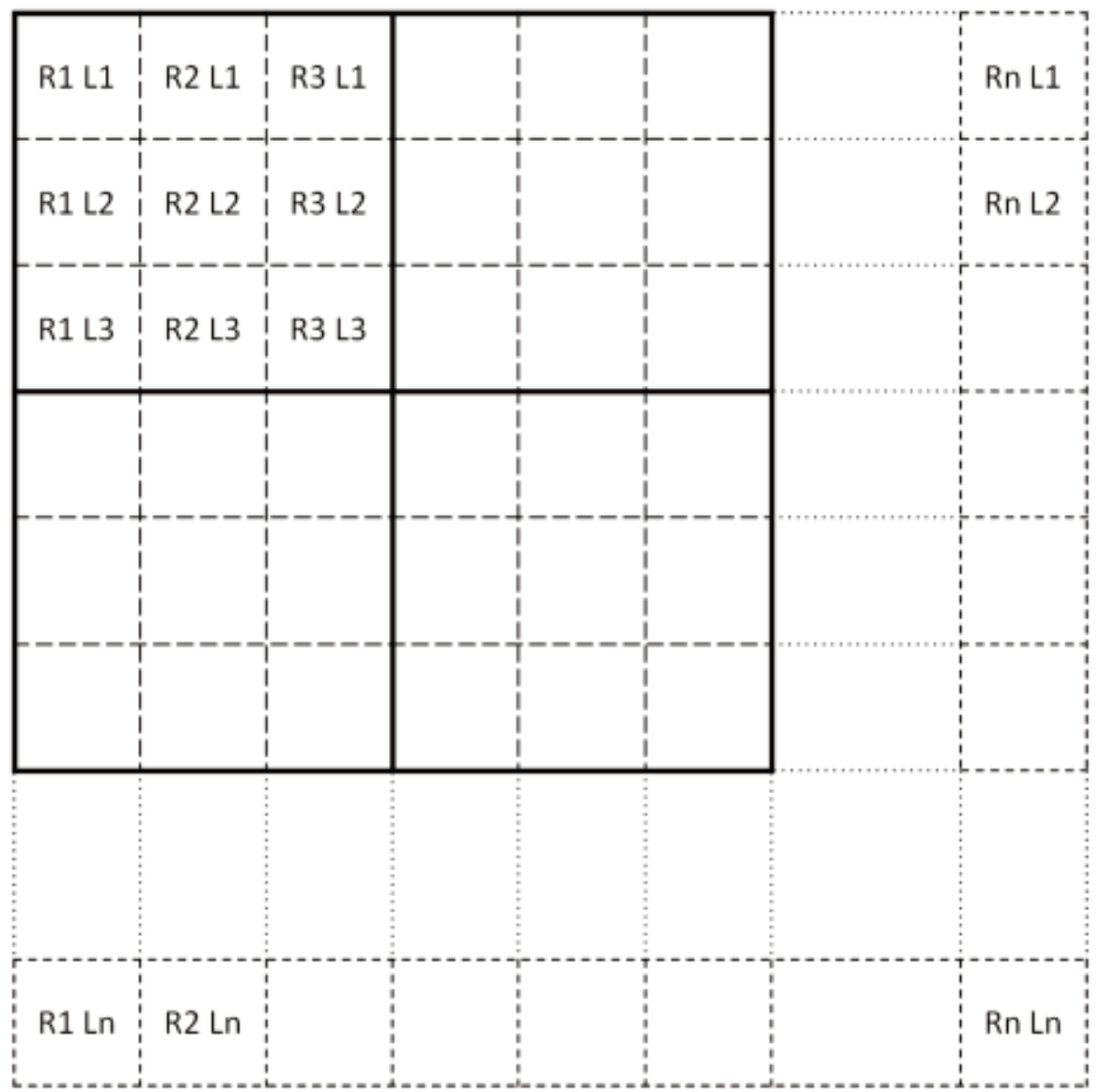

Figure 1. Schematic representation of the applied spatial filter. Dashed lines represent the original full resolution SEVIRI pixels; instead, continuous lines the downscaled resolution SEVIRI pixels. Every three pixels the spatial mean value has been computed only if 5 out of 9 pixels within a region of $3 \times 3$ pixels centered on the considered pixel were not affected by clouds.

\subsection{Significant Sequence of TIR Anomalies (SSTA) and their possible relations with earthquake occurrence}

In this study, nighttime (i.e. time slot 00:00-00:15 GMT) images acquired by the sensor SEVIRI (Spinning Enhanced Visible and Infrared Imager) on board MSG (Meteosat Second Generation) satellite in the Thermal InfraRed (TIR) spectral range (i.e. IR10,8 channel at 9,80-11,80 $\mu \mathrm{m}$ ) from June 2004 to December 2014 over the Italian peninsula (top-left $47.07^{\circ} \mathrm{N}-6.08^{\circ} \mathrm{E}$; top-right $47.7^{\circ} \mathrm{N}-22.4^{\circ} \mathrm{E}$; bottom-right $35.9^{\circ} \mathrm{N}-18.05^{\circ} \mathrm{E}$; bottom-left $35.6^{\circ} \mathrm{N}-4.9^{\circ} \mathrm{E}$ ) have been organized in monthly reference datasets and used to compute the reference fields. Both indexes, i.e. RETIRA and RETIRA ${ }_{\text {box }}$, have been computed for all TIR images belonging to the MSG/SEVIRI datasets, producing in this manner daily Thermal Anomaly Map (TAM) to be analyzed.

In addition to Thermal Anomalies (TAs) possibly related to seismic activities, other natural and/or observational conditions could generate a proliferation of TAs in the TAMs, such as night-time cloud passages and errors in image navigation/co-location processes [Aliano et al., 2008a]. In both cases, these TAs have a tendency to vanish with the time and/or to be restricted in some geographical regions (i.e. along the coastlines). This particular character allows us to distinguish them from TAs possibly related to an impending earthquake, which are spatially and temporally persistent [Tramutoli et al., 2005]. Like the previous RST applications to satellite thermal monitoring of seismic areas, a space-time persistence analysis has been carried out with the aim to qualify TAs highlighted by the RST methodology as Significant Thermal Anomalies [STAs; Eleftheriou et al., 2016; Genzano et al., 2015; Tramutoli et al., 2015b], which could be part of a Significant Sequence of Thermal Anomalies (SSTA).

So, each single location $(\boldsymbol{r})$ has been considered (at the time of observation $t^{\prime}$ ) to be part of an SSTA, if it 
satisfies the following requirements:

- relative intensity: the TA should have a value of the RST-based index ${ }^{3} \geq \mathrm{K}$ (in this study $\mathrm{K}=3.5$ );

- spurious effects are discarded: portions (i.e. land or sea) of the TAMs affected by a wide cloudy coverage (in this study we considered useful only land/sea portions of the scene having a fraction of cloudy pixels less than 80\%), navigation errors [Filizzola et al., 2004] and known spurious effects [e.g. cold spatial average effect, in this study identified by this condition $T(t) \leq \mu_{T}-2 \sigma_{T}$; see Aliano et al., 2008a; Genzano et al., 2009a, 2015; Eleftheriou et al., 2016 for more details] are discarded from the subsequent analyses;

- persistence in space-time domain: the existence of a group of STAs which cover at least $150 \mathrm{~km}^{2}$ within an area of $1 \times 1^{\circ}$ around $\boldsymbol{r}$ (spatial persistence) and reappear at least one more time in the 7 days preceding/following $t$ (temporal persistence).

The possible space-time relations among the appearances of SSTAs and time, location and magnitude of earthquakes ${ }^{4}$ occurred in the same space-time period have been evaluated applying empirical rules. Taking in account both the existing genetic models up to now proposed to explain the origin of TAs [see for example Tramutoli et al., 2013] and the results reported in the previous studies [a summary is reported in Tramutoli el al., 2015, 2018a], each single STA observed at the time $t$ in the location $(\boldsymbol{r})$ will be considered possibly related to seismic activity if:

- it belongs to a previously identified SSTA;

- an earthquake of $\mathrm{M} \geq 4$ occurs 30 days after its appearance or within 15 days before (temporal window);

- an earthquake with $M \geq 4$ occurs within a distance $D$, from the considered STA, where $D=R_{D}$ being $R_{D}=10^{0.43 M}$ the Dobrovolsky et al., [1979] distance (spatial window). On the basis of the previous discussion, it is assumed $\mathrm{D}=150 \mathrm{~km}$ for $\mathrm{M} \leq 5$.

\section{Results}

Figure 2 reports a comparison between the TAMs obtained by the two RST analyses. In both cases, the TAs that are not due to spurious effects, with a spatial extension and temporal continuity suitable for classifying them as STAs belonging to an SSTA, appear in the central part of Italy on March 30 and March 31, 2009. Looking at Figure 2, it is possible to note that:

- moving from TIR images at full resolution to downscaled TIR images, TAs indentified by using the RETIRA or the RETIRA $A_{\text {box }}$ index with the same $\mathrm{S} / \mathrm{N}$ ratio (i.e. $\mathrm{S} / \mathrm{N} \geq 3.5$ ) appear in the same regions (on March 30 over the eastern part of Abruzzo/Marche region and on March 31 over the Central Apennines). Moreover, in the TAMs

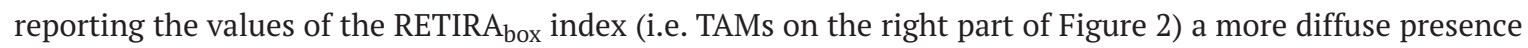
of STAs with an $\mathrm{S} / \mathrm{N} \geq 4.5$ can be noted. Both circumstances indicate that the applied spatial filtering does not produce a significant loss of information, but it preserves and emphasizes (in terms of S/N) those STAs with an appreciable spatial extension (i.e. $\geq 150 \mathrm{~km}^{2}$ );

- several earthquakes with magnitude greater than 4 (including the L’Aquila earthquake of magnitude $\mathrm{M}_{\mathrm{W}} \sim 6.3$ happened on April 6, 2009) occurred inside the spatial window of $150 \mathrm{~km}$ from the STAs and in the temporal window March 28, 2009 - April 23, 2009.

By applying the aforementioned rules to all TAMs obtained by applying the RST methodology and computing both

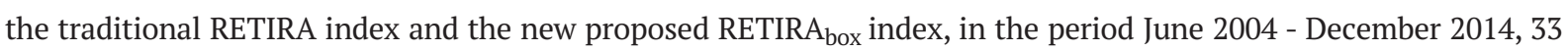

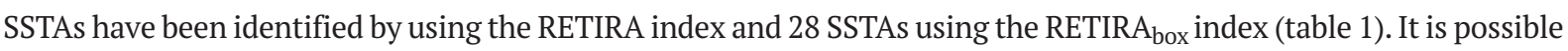
to note that 27 of 33 SSTAs identified by using the RETIRA index are also identified by using the RETIRA box $_{\text {index. The }}$ remaining 6 SSTAs disappear when RETIRA box $_{\text {is }}$ ised because STAs do not satisfy the requirements of relative intensity and/or persistence in space-time domain; on the contrary only 1 SSTA has been identified by using RETIRA box $_{\text {but }}$ is not is identified by using the traditional RETIRA index.

3 The RETIRA index in the case of SEVIRI TIR images at full resolution; RETIRA $\mathrm{box}_{\text {in }}$ in the case of SEVIRI TIR downscaled images using a $3 \times 3$ pixel box.

${ }^{4}$ As reported in the ISIDe (Italian Seismological Instrumental and parametric DatabasE) earthquake catalogue (ISIDe working group, 2016) from May 15,2004 to January 30,2015 in the area top-left $48.07^{\circ} \mathrm{N}-5.08^{\circ} \mathrm{E}$, top-right $48.7^{\circ} \mathrm{N}-23.4^{\circ} \mathrm{E}$, bottom-right $34.9^{\circ} \mathrm{N}-19.05^{\circ} \mathrm{E}$, bottom-left $34.6^{\circ} \mathrm{N}-3.9^{\circ} \mathrm{E} 656$ events of $\mathrm{M} \geq 4,38$ events of $\mathrm{M} \geq 5$ and 1 event of $\mathrm{M} \geq 6$. 


\section{Nicola Genzano et al.}

MSG-SEVIRI full resolution

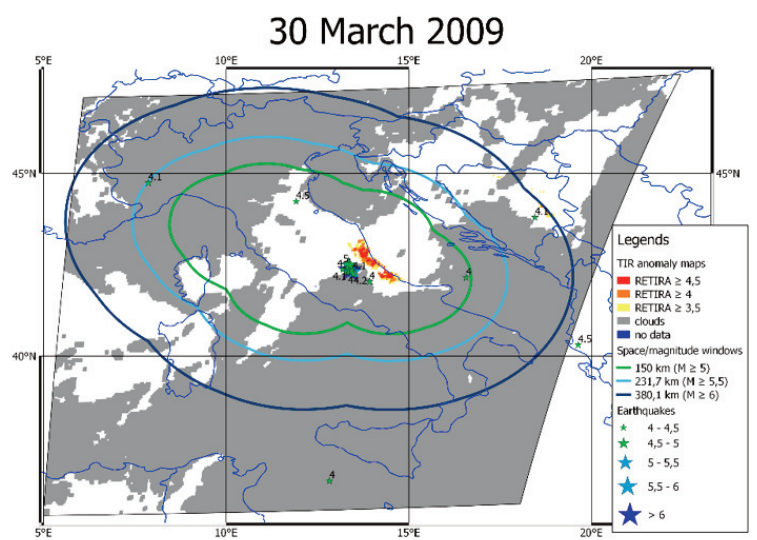

31 March 2009

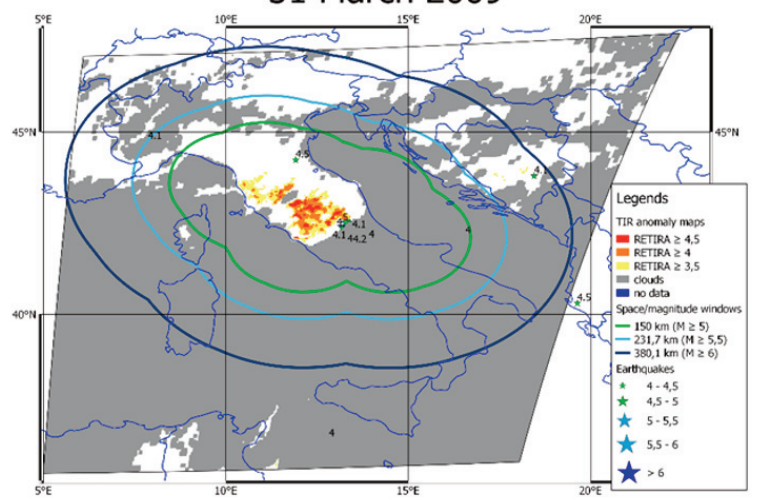

MSG-SEVIRI box 3×3

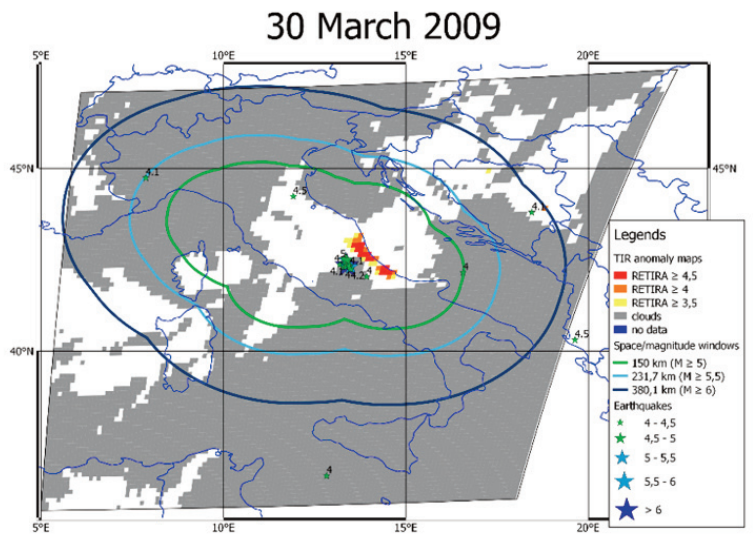

31 March 2009

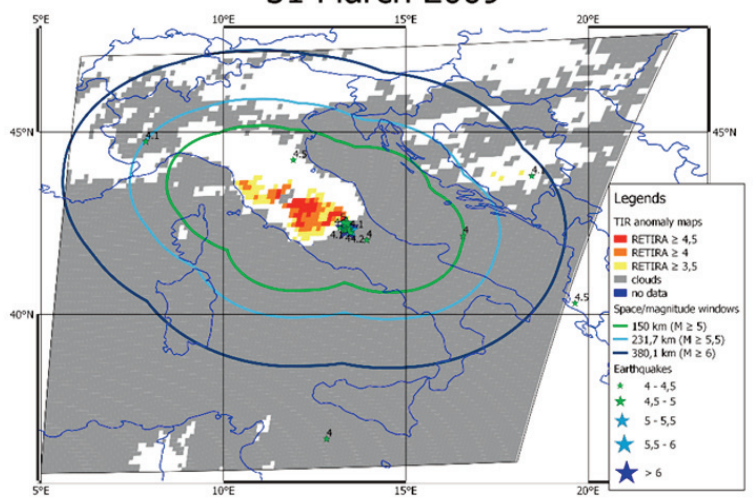

Figure 2. Comparison between Thermal Anomalies Maps (TAMs) obtained by the two RST analyses. On the left side, a Significant Sequence of Thermal Anomalies (SSTA) identified by applying the RST approach on SEVIRI TIR images at full resolution, while on the right side the corresponding SSTA identified by apply the RST approach on SEVIRI TIR images at the downscaled resolution. In both cases, TIR anomalies $(\mathrm{S} / \mathrm{N} \geq 3.5)$ are depicted in different colors according to the RETIRA (or RETIRA $A_{\text {box }}$ ) index values and clouds are depicted in gray. Contours in different colors correspond to different space/magnitude windows (see text) and stars correspond to earthquakes. Significant TIR anomalies (i.e. not due to spurious effects, with spatial extension and temporal continuity) appear in the central part of Italy on March 30 and March 31, 2009, respectively 7 and 6 days before L'Aquila earthquake (MW 6.3) happened on April 6, 2009. 
To develop a multi parametric system for short-term SHA in Italy

\begin{tabular}{|c|c|c|c|c|c|c|c|c|}
\hline \multirow{2}{*}{ Id } & \multirow{2}{*}{ Place } & \multirow{2}{*}{$\begin{array}{c}\text { Period } \\
\text { (From-to) }\end{array}$} & \multicolumn{3}{|r|}{ RST and RETIRA } & \multicolumn{3}{|r|}{ RST and RETIRA $A_{\text {box }}$} \\
\hline & & & SSTA & EQs & Mag (Time lag FTA) & SSTA & EQs & Mag (Time lag FTA) \\
\hline 1 & South Italy (Campania) & Aug 21-25,2004 & $\mathrm{Y}$ & $\mathrm{Y}$ & $4(+13)$ & $\mathrm{N}$ & & \\
\hline 2 & North-East Italy & Dec 1-3, 2004 & $\mathrm{Y}$ & $\mathrm{N}$ & & $\mathrm{N}$ & & \\
\hline 3 & Central Italy (Marche) & Dec 3-10, 2004 & $\mathrm{Y}$ & $\mathrm{Y}$ & $\begin{array}{c}4.2(0), 4.5(+1), 4.3(+6) \\
4.2(+14), 4.4(-4), 4.3(-4) \\
4.9(-8), 4.4(-8), \text { n. } 24.1(-8)\end{array}$ & $\mathrm{Y}$ & $\mathrm{Y}$ & $\begin{array}{c}4.2(0), 4.5(+1), 4.3(+6) \\
4.2(+14), 4.4(-4), 4.3(-4) \\
4.9(-8), 4.4(-8), \text { n. } 24.1(-8)\end{array}$ \\
\hline 4 & North Africa (Tunisia) & Mar 24-26, 2005 & $\mathrm{Y}$ & $\mathrm{N}$ & & $\mathrm{Y}$ & $\mathrm{N}$ & \\
\hline 5 & South Italy (Sicily) & May 11-14, 2005 & $\mathrm{Y}$ & $\mathrm{N}$ & & $\mathrm{Y}$ & $\mathrm{N}$ & \\
\hline 6 & North Africa (Algeria) & $\begin{array}{l}\text { Aug } 10-18,2005^{*} \\
\text { Aug } 10-11,2005\end{array}$ & Y & $\mathrm{Y}$ & $4.2(+27)$ & $\mathrm{Y}^{*}$ & $\mathrm{Y}$ & $4.2(+27)$ \\
\hline 7 & South Italy (Calabria) & Aug 12-13,2005 & $\mathrm{Y}$ & $\mathrm{Y}$ & $4.5(+2), 4(-9)$ & $\mathrm{Y}$ & $\mathrm{Y}$ & $4.5(+2)$ \\
\hline 8 & North Africa (Tunisia) & April 1-2,2006 & $\mathrm{Y}$ & $\mathrm{N}$ & & $\mathrm{Y}$ & $\mathrm{N}$ & \\
\hline 9 & $\begin{array}{c}\text { South Italy } \\
\text { (Sicily/Calabria) }\end{array}$ & May 23-27, 2005 & Y & $\mathrm{Y}$ & $\begin{array}{c}4.2(+7), 4(+21), 4.5(+30) \\
4.1(-3)\end{array}$ & $\mathrm{Y}$ & Y & $\begin{array}{c}4.2(+7), 4(+21), 4.5(+30) \\
4.1(-3)\end{array}$ \\
\hline 10 & Sea of Sicily & Jun 22-23, 2006 & $\mathrm{Y}$ & $\mathrm{N}$ & & $\mathrm{Y}$ & $\mathrm{N}$ & \\
\hline 11 & North Africa & Jun18-26, 2007 & $\mathrm{Y}$ & $\mathrm{Y}$ & $4(-9), 4.1(-15)$ & $\mathrm{Y}$ & $\mathrm{Y}$ & $4(-9), 4.1(-15)$ \\
\hline 12 & $\begin{array}{c}\text { South Italy } \\
\text { (Apulia/Calabria) }\end{array}$ & Jun 22-28, 2007 & Y & $\mathrm{Y}$ & $5.2(+12), 4(+30)$ & $\mathrm{Y}$ & $\mathrm{Y}$ & $5.2(+12)$ \\
\hline 13 & Balkan region & $\begin{array}{l}\text { July } 23-25,2007^{*} \\
\text { July } 22-25,2007\end{array}$ & Y & Y & $4.1(+16), 4(+28), 4.2(-5)$ & $\mathrm{Y}^{*}$ & $\mathrm{Y}$ & $4.1(+17), 4(+29), 4.2(-4)$ \\
\hline 14 & South Italy & Aug 19 - Sept. 1, 2007 & $\mathrm{Y}$ & $\mathrm{Y}$ & $4.1(+34), 4(-1)$ & $\mathrm{Y}$ & $\mathrm{Y}$ & $4.1(+34), 4(-1)$ \\
\hline 15 & South Italy (Sicily) & Jun 17-18, 2008 & Y & $\mathrm{Y}$ & $4.2(+16)$ & $\mathrm{Y}$ & $\mathrm{Y}$ & $4.2(+16)$ \\
\hline 16 & South Italy (Calabria) & Aug 9-16, 2008 & $\mathrm{Y}$ & $\mathrm{N}$ & & $\mathrm{N}$ & & \\
\hline 17 & S. Italy (St of Messina) & Sep 9-15, 2008 & Y & $\mathrm{Y}$ & $4(+18)$ & $\mathrm{Y}$ & $\mathrm{Y}$ & $4(+18)$ \\
\hline 18 & South Italy (Campania) & Jan 2-9, 2009 & $\mathrm{Y}$ & $\mathrm{Y}$ & $4(-3)$ & $\mathrm{N}$ & & \\
\hline 19 & Central Italy (Abruzzo) & Mar 30-31, 2009 & Y & Y & $\begin{array}{c}4(0), 4.5(+6), 4(+6), 6.3(+7), \\
5(+7), 4.8(+7), 4.7(+7), \text { n. } 24.3(+7), \\
\text { n.3 } 4.2(+7), \text { n. } 44.1(+7), \\
4(+7), 5.4(+8), 4.9(+8), 4.3(+8) \\
\text { n.2 } 4.1(+9), 5.2(+10), 5(+10) \\
4.2(+10), 4.1(+10), \text { n.2 } 4(+10) \\
4(+11), 4.8(+14), 4.1(+15) \\
4.2(+24), 4(+24), 4(-1), 4(-2)\end{array}$ & 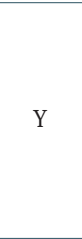 & Y & $\begin{array}{c}4(0), 4.5(+6), 4(+6), 6.3(+7), \\
5(+7), 4.8(+7), 4.7(+7), \text { n.2 } 4.3(+7), \\
\text { n.3 4.2 }(+7), \text { n. } 44.1(+7), \\
4(+7), 5.4(+8), 4.9(+8), 4.3(+8), \\
\text { n.2 4.1(+9), 5.2 }(+10), 5(+10), \\
4.2(+10), 4.1(+10), \text { n.2 } 4(+10), \\
4(+11), 4.8(+14), 4.1(+15), \\
4.2(+24), 4(+24), 4(-1), 4(-2)\end{array}$ \\
\hline 19bis & Balkan region & Mar 30-31, 2009 & $\mathrm{~N}$ & & & $\mathrm{Y}$ & $\mathrm{Y}$ & $4.1(+1), 6.3(+7)$ \\
\hline 20 & Adriatic sea & May 26-28, 2009 & $\mathrm{Y}$ & $\mathrm{Y}$ & $4.8(+26), 4.4(+27), 4(+28)$ & $\mathrm{Y}$ & $\mathrm{Y}$ & $4.8(+26), 4.4(+27), 4(+28)$ \\
\hline 21 & Sardinia & Jul 23-24, 2009 & $\mathrm{Y}$ & $\mathrm{N}$ & & $\mathrm{Y}$ & $\mathrm{N}$ & \\
\hline 22 & Central Italy & Jul 24-25, 2009 & $\mathrm{Y}$ & $\mathrm{Y}$ & $4(+13), 4.2(-2)$ & $\mathrm{Y}$ & $\mathrm{Y}$ & $4(+13), 4.2(-2)$ \\
\hline 23 & South Italy & Jul 25-26, 2009 & Y & $\mathrm{N}$ & & $\mathrm{Y}$ & $\mathrm{N}$ & \\
\hline 24 & North Africa & Jul 23-29, 2009 & $\mathrm{Y}$ & $\mathrm{N}$ & & $\mathrm{Y}$ & $\mathrm{N}$ & \\
\hline 25 & North Africa & Feb. 28-Mar 3, 2010 & $\mathrm{Y}$ & $\mathrm{N}$ & & $\mathrm{Y}$ & $\mathrm{N}$ & \\
\hline 26 & Ligurian sea & May 25-27, 2011 & $\mathrm{Y}$ & $\mathrm{N}$ & & $\mathrm{Y}$ & $\mathrm{N}$ & \\
\hline 27 & Balkan region & Jul 15-20, 2011 & $\mathrm{Y}$ & $\mathrm{Y}$ & $4.1(-1)$ & $\mathrm{N}$ & & \\
\hline 28 & North Africa (Algeria) & May 18-19, 2012 & Y & $\mathrm{Y}$ & $4(+16)$ & $\mathrm{Y}$ & Y & $4(+16)$ \\
\hline 29 & Balkan region & Sep 1-3, 2012 & $\mathrm{Y}$ & $\mathrm{N}$ & & $\mathrm{N}$ & & \\
\hline 30 & North Africa & Sep 22-23, 2012 & $\mathrm{Y}$ & $\mathrm{Y}$ & $4.6(+18)$ & $\mathrm{Y}$ & $\mathrm{Y}$ & $4.6(+18)$ \\
\hline 31 & Balkan region & Sep 25-30, 2012 & $\mathrm{Y}$ & $\mathrm{Y}$ & $4.4(+13)$ & $\mathrm{Y}$ & $\mathrm{Y}$ & $4.4(+13)$ \\
\hline 32 & South Italy (Sicily) & Apr 29 - May 5, 2013 & $\mathrm{Y}$ & $\mathrm{N}$ & & $\mathrm{Y}$ & $\mathrm{N}$ & \\
\hline \multirow[t]{2}{*}{33} & North Africa & Oct 4-6, 2013 & $\mathrm{Y}$ & $\mathrm{Y}$ & $4.4(+14)$ & $\mathrm{Y}$ & $\mathrm{N}$ & \\
\hline & & & $\begin{array}{c}33 \\
\text { SSTA }\end{array}$ & $\begin{array}{l}20 \mathrm{Y} \\
13 \mathrm{~N}\end{array}$ & $60.6 \%$ Y $39.4 \%$ N & $\begin{array}{c}28 \\
\text { SSTA }\end{array}$ & $\begin{array}{l}17 \mathrm{Y} \\
11 \mathrm{~N}\end{array}$ & $60.7 \%$ Y $39.3 \%$ N \\
\hline
\end{tabular}

Table 1. Summary of the correlation analyses. 


\section{Nicola Genzano et al.}

As announced in the previous paragraph, the possible relation between the highlighted SSTAs and occurred $M \geq 4$ earthquakes has been verified on the basis of pre-established rules. The long-term correlation analysis highlights that in both RST analyses more than $60 \%$ of SSTAs is in a space-time relation with the occurred earthquakes, with a remain $\sim 40 \%$ of SSTAs apparently not related to documented seismic activity. Moreover, looking at Figure 3, it is possible to note that more than the $80 \%$ of SSTAs associable to earthquakes has tendency to anticipate the occurrence of earthquakes (more than the $50 \%$ of them appears only before earthquakes and not before and after).

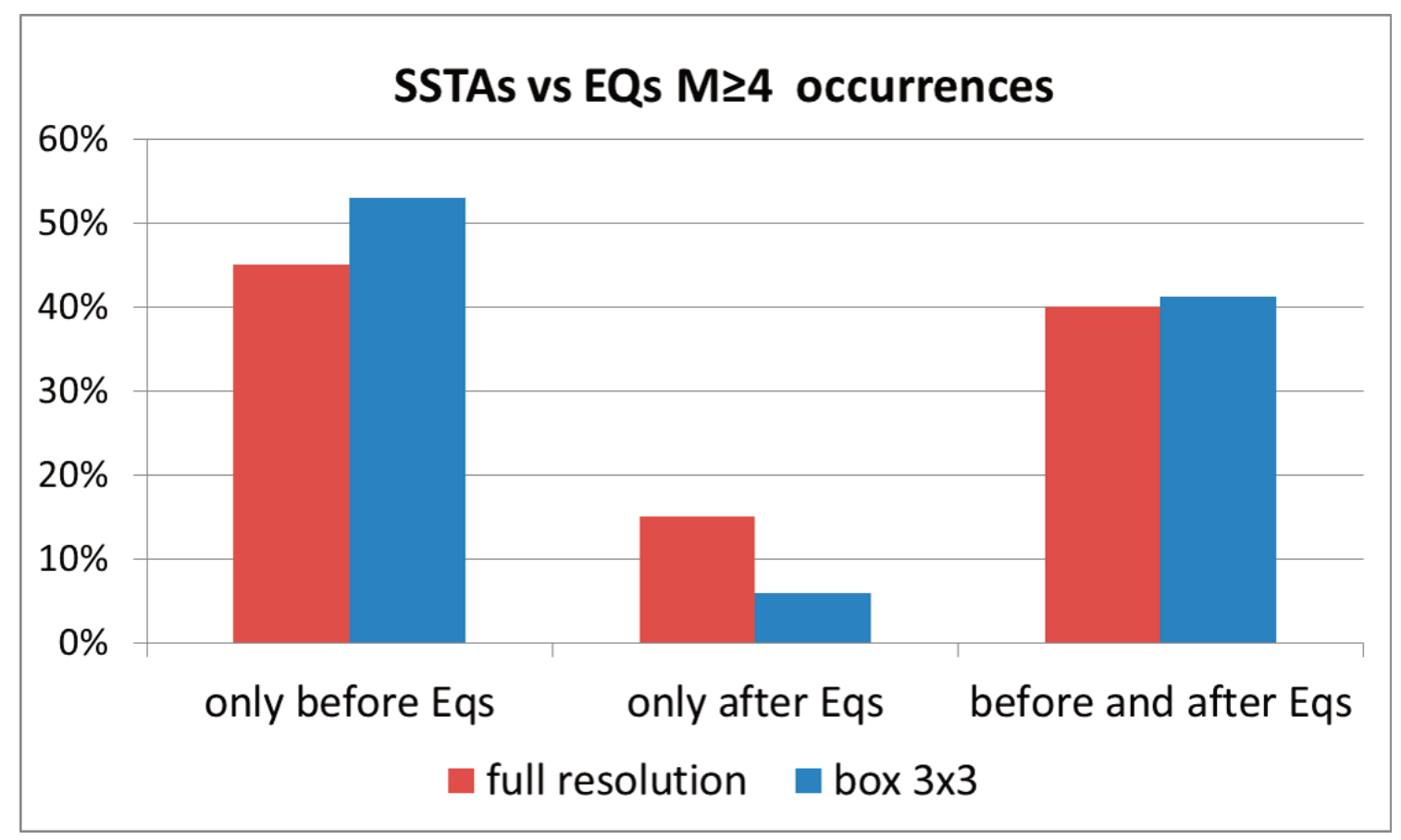

Figure 3. Distribution of the SSTAs compared to earthquake occurrences. For both analysis, more than the $80 \%$ of SSTAs associable to earthquakes has tendency to anticipate the occurrence of earthquakes.

With the aim to reveal possible periodicities and characteristics between seismic events and the SSTAs identified

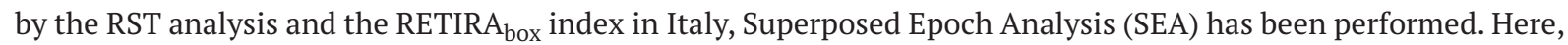
the SEA approach has been implemented by comparing the time of the occurrences of earthquakes associable to SSTAs (i.e. that satisfy the used empirical rules) with the time of the occurrences of First STA (FSTA) appearances. Here, clusters of earthquakes have been considered as daily single events and the temporal interval between earthquake occurrence and FSTA has been aggregated on the basis of two day counts. Moreover, in order to verify particular tendency of different types of earthquake (i.e. events due to normal faulting or due to reverse faulting), results of the SEA analysis have been differentiated on the basis of earthquake focal mechanisms. The type of faulting of those earthquakes that show some space-time relations with identified SSTAs has been established consulting the Italian CMT [Centroid Moment Tensor; Pondrelli et al., 2006] dataset for Italy and the Global CMT catalogue [Dziewonski et al., 1981; Ekström et al., 2012] and the European-Mediterranean RCMT catalogue [Pondrelli et al., 2002] for Balkan and North Africa regions. For the seismic events where moment tensor solution is not computed, the type of faulting has been established in accord with the local tectonic regime of the specific geographical region where earthquake has happened, on the basis of seismic source zone model ZS9 proposed by Meletti et al., [2008]. Results of the SEA analysis shown in Figure 4 highlight that more than $45 \%$ of considered earthquakes occurs within a temporal window of two weeks after the first appearances of the significant thermal anomalies and that the $50 \%$ of them is due to normal faulting, which corresponds to the $66 \%$ of all events due to normal faulting. 


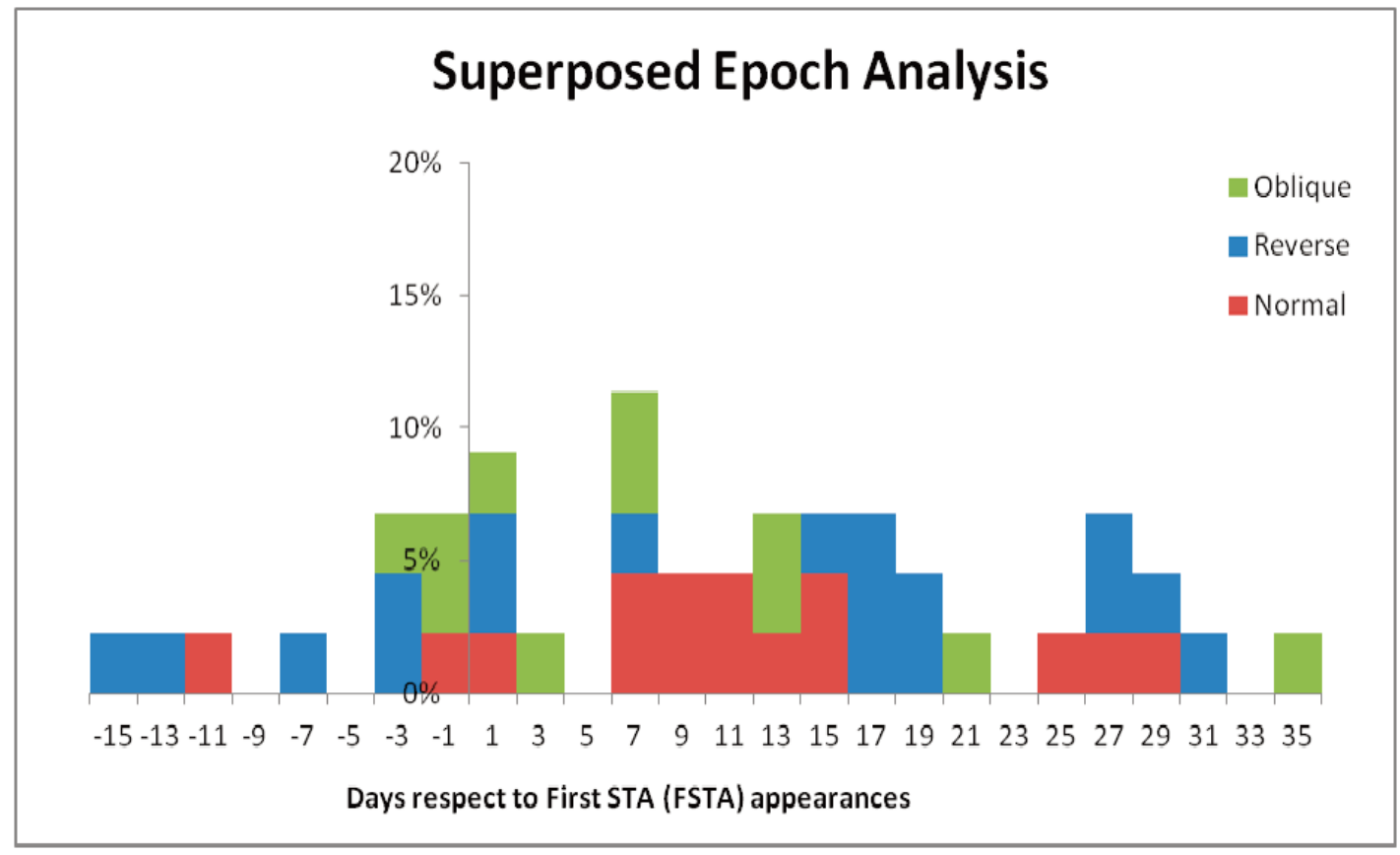

Figure 4. Superposed Epoch Analysis (SEA) between the SSTAs identified by the RST analysis and the RETIRA box $_{\text {index and }}$ the seismic events occurred in the investigated region and period. Results have been differentiated on the basis of earthquake focal mechanisms (red indicates earthquakes due to normal faulting, blue earthquakes due to reverse faulting and green earthquakes due to not predominant faulting type, i.e. oblique).

In order to verify the non-causality of achieved results, an adapted Molchan error diagram approach [Molchan 1990, 1991, 1997; Molchan and Kagan, 1992] has been performed. As proposed in the study of Eleftheriou et al. [2016], Molchan error diagram was implemented by plotting the fraction of missed earthquakes (i.e. apparently not preceded/followed by SSTAs) $n(M)$ against the fraction of alerted space-time volume $\tau(M)$, which were computed as in the following expressions:

$$
v(\mathrm{M})=\frac{\text { Number of EQs with magnitude } \geq M \text { outside the correlation window (missed) }}{\text { Total number of EQs with magnitude } \geq M \text { occurred within the whole space } \times \text { time investigated volume }}
$$

$$
\tau(\mathrm{M})=\frac{\text { Alerted space } \times \text { time volume for } \mathrm{EQs} \text { with magnitude } \geq M}{\text { Whole investigated space } \times \text { time volume }}
$$

Figure 5 reports the Molchan error diagrams for both long-term correlation analyses. The left side of Figure 5 shows the results achieved taking in account SSTAs identified by using the RETIRA index, while on the right side there are the results obtained considering the SSTAs identified by using the RETIRA $A_{b o x}$ index. In addition, for classes of magnitude $M \geq 4$ and $M \geq 5^{5}$, confidence limit curves surrounding the diagonal of random guess have been computed and plotted. In this study, confidence levels of $95 \%$ are used to indicate "significant" deviation from random guessing based on the null-hypothesis [see Kossobokov 2006 for more details].

Taking in mind that a proliferation of missed events could occur, due to large and persistent meteorological clouds, as well as the data missing, which prevent from fully appreciating and monitoring with continuity the occurrence of all possible STAs, looking at Figure 5 it is possible to note that a non-casual correlation between SSTAs and earthquakes exists. In fact, by comparison with random guess line (i.e. diagonal of Molchan diagram), both in the case of earthquakes

\footnotetext{
${ }^{5}$ Confidence limit is not computed for $\mathrm{M} \geq 6$ because only 1 event does not allow us to attribute any statistical significance.
} 


\section{Nicola Genzano et al.}

that follow the SSTAs (full circles/triangles) and in the case of earthquakes that follow or precede the SSTAs (empty circles/triangles), all considered strategies (i.e. various classes of earthquake magnitude and spatial correlation windows) are in the optimal strategy zone (i.e. below the random guess line). In both cases, achieved statistics do not reject the null-hypothesis of random guessing at the significant level $\alpha=5 \%$ (i.e. the accepted significance level for this kind of study). In fact, in this study it is $\alpha=14,8 \%$ in the case of analysis at full resolution and $\alpha=17,2 \%$ in the case of analysis at downscaled resolution. Finally, although the measurement of the probability gain (G) is not trivial [see Molchan, 1991], an attempt to estimate $G$ has been done following the Aki's paper [Aki, 1989]. Results highlight that a probability gain, which was computed as $\mathrm{G}=(1-v) / \tau$ ) up to 4,9 (for $\mathrm{M} \geq 5$ earthquakes), can be achieved if only pre-seismic SSTAs identified by using the RETIRA index are considered, and up to $6.2^{6}$ for the same classes of earthquake magnitude but considering SSTAs identified by using the RETIRA ${ }_{\text {box }}$ index.

Full resolution analysis

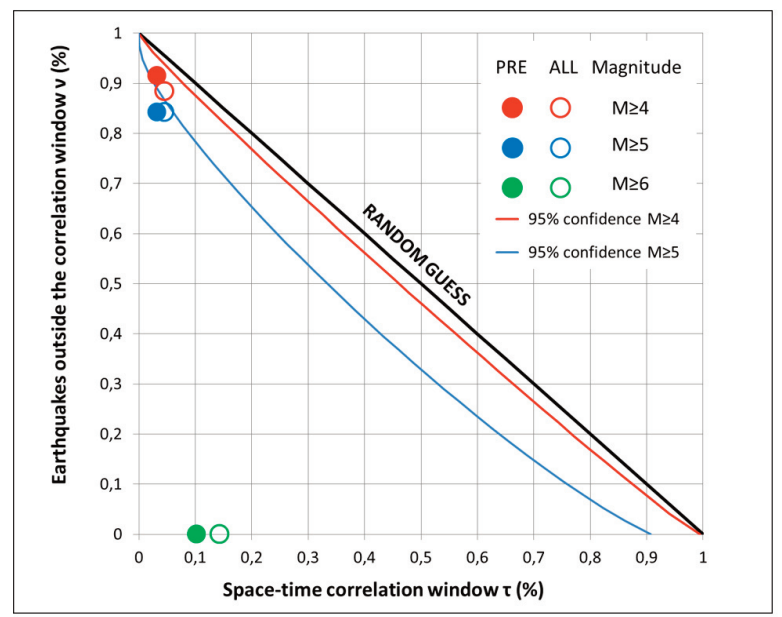

Box $3 \times 3$ analysis

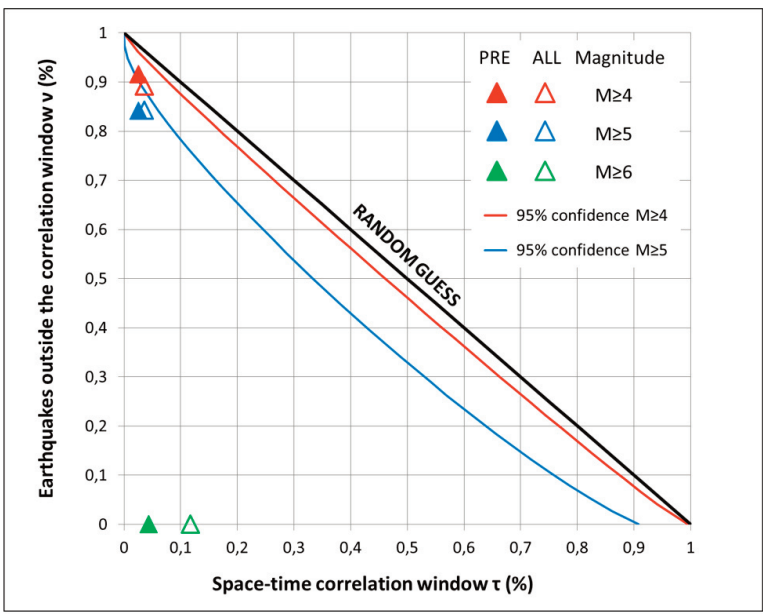

Figure 5. On the left side, Molchan error diagram analysis computed for different classes of magnitude and SSTA identified by applying the RST approach on SEVIRI TIR images at full resolution on the whole study period (2004-2014), while on the right side the corresponding Molchan error diagram computed to SSTA identified by applying the RST approach on SEVIRI TIR images at downscaled resolution. Full circles and full triangles refer to earthquakes occurred only after the appearances of SSTAs (pre-seismic anomalies). Empty circles and empty triangles refer to earthquakes occurred before or after the appearances of SSTAs (earthquake-related anomalies). Red line and blue line indicate the $95 \%$ confidence limit curves surrounding the diagonal of random guess for earthquakes with magnitudes greater than 4 and 5 , respectively.

In comparison with results achieved by using the traditional RETIRA index, when the RETIRA $\mathrm{box}_{\text {is }}$ used to identify STAs:

- more than $81 \%$ of SSTAs survives;

- more than $60 \%$ of SSTAs is apparently in connection with the occurrence of $M \geq 4$ earthquakes;

- an improvement in terms of probability gain up to 6.2 as compared to random guess is achieved.

\section{Conclusion}

With the aim to define a multi-parametric system able to improve our capabilities to provide short-term (from days to weeks) seismic hazard forecasting, in this paper we have studied the potentiality and the capabilities of the

\footnotetext{
${ }^{6}$ It should be noted that for magnitudes greater than 6 a higher probability gain is achievable, but the little data sample does not allow us any statistical significance to be attributed to it.
} 
parameter "Earth's thermally emitted radiation measured by satellite sensors in the Thermal InfraRed (TIR) spectral region" to provide useful information about the seismic process.

To this purpose, on the basis of 11 years of MSG/SEVIRI TIR records collected over Italian peninsula, we have evaluated the level of correlation between the occurrence of earthquakes with magnitude greater than 4 and satellite TIR anomalies highlighted by Robust Satellite Techniques (RST). Moreover, for the first time, with the aim to reduce the proliferation of spurious TIR anomalies, due to other causes independent from the seismic activity (e.g. extended

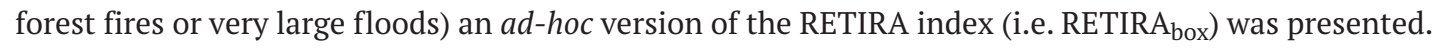

To evaluate its accuracy, the same TIR SEVIRI time series (from June 2004 to December 2014) has been analysed computing both the RETIRA and the RETIRA $A_{\text {box }}$ index. Results of the two RST analyses have shown that the $82 \%$ (i.e. 27 of 33) of the identified SSTAs does not disappear when a downscaled spatial resolution SEVIRI TIR records was used. These circumstances confirm that the low spatial resolution is not a constraint to monitor possible preseismic thermal anomalies; in fact, large-scale phenomena (e.g. Earth degassing) continue to produce TIR anomalies also in larger size pixels.

Results of correlation analyses performed applying pre-established rules highlight that in both the RST analyses:

- more than $60 \%$ of SSTAs is in a space-time relation with the occurred earthquakes, with a remaining $\sim 40 \%$ of SSTAs apparently not related to documented seismic activity (false positives);

- more than the $80 \%$ of SSTAs associable to earthquakes has tendency to anticipate the occurrence of earthquakes, with a $50 \%$ of them appearing only before earthquakes and not before and after the seismic events;

- superposed epoch analysis indicates that more than $45 \%$ of earthquakes associable to SSTAs occurs within a temporal window of two weeks after the first appearance of the significant thermal anomalies.

Taking in mind the intrinsic technological limitation represented by the presence of meteorological clouds, which prevent from appreciating space-time continuity of observed thermal anomalies and consequently which can produce an overestimation of missed events, the results of Molchan's error diagrams show a precursory correlation in both performed analyses. Moreover, moving from the analysis of TIR SEVIRI time series at full pixel resolution (i.e. SSTAs identified by using the RETIRA index) to the analysis at a downscaled spatial resolution (i.e. SSTAs identified by using the RETIRA $A_{\text {box }}$ index), an increase of probability gain has been obtained.

Finally, results achieved in this work confirm that satellite TIR anomalies highlighted by the RST approach and the RETIRA-based indexes provide useful information on seismic processes and oncoming earthquakes. Although a long-term correlation analysis shows an intermediate number of false positives, on the basis of random test analysis (i.e. Molchan diagram) we can conclude that the parameter "RST-based satellite TIR anomalies" can be included in the framework of multi-parameter systems devoted to short-term earthquake forecast [Tramutoli et al., 2014], which should be based on well-founded observational methodologies and data analysis techniques. So, thanks to the systematic integration of the short-term observations with the traditional approaches (e.g. based on seismological catalogues) devoted to defining a probabilistic assessment of the seismic hazard in the long-term, it could be expected an increase in terms of reliability and precision of seismic hazard assessment, which can be systematically updated on the basis of the specific alerted space-time windows and predictive capabilities of the considered parameters.

Acknowledgements. The authors wish to thank the Aeronautica Militare Italiana for its support to have access to MSGSEVIRI data used in this work.

\section{References}

Aki, K. (1989). Ideal probabilistic earthquake prediction, Tectonophysics 169:197-198. doi:10.1016/00401951(89)90193-5.

Aliano, C., Corrado R., Filizzola C., Pergola N., and Tramutoli V. (2007). Robust Satellite Techniques (RST) for Seismically Active Areas Monitoring: the Case of 21st May, 2003 Boumerdes/Thenia (Algeria) Earthquake. 2007, Int. Work. Anal. Multi-temporal Remote Sens. Images. IEEE, 1-6.

Aliano, C., Corrado R., Filizzola C., Genzano N., Pergola N., and Tramutoli V.(2008a). Robust TIR satellite techniques for 


\section{Nicola Genzano et al.}

monitoring earthquake active regions: limits, main achievements and perspectives, Ann. Geophys., 51, 303-317.

Aliano, C., Corrado R., Filizzola C., Pergola N., and Tramutoli V. (2008b). Robust satellite techniques (RST) for the thermal monitoring of earthquake prone areas: the case of Umbria-Marche October, 1997 seismic events, Ann. Geophys., $51,451-459$.

Blackett, M., Wooster M., and Malamud B.D. (2011). Exploring land surface temperature earthquake precursors: A focus on the Gujarat (India) earthquake of 2001, Geophys. Res. Lett., 38(15), 1-8. http://doi.org/10.1029/2011GL048282.

Choudhury, S., Dasgupta S., Saraf A.-K., and Panda S. (2006). Remote sensing observations of pre-earthquake thermal anomalies in Iran, Int. J. Remote Sens., 27, 4381-4396, doi:10.1080/01431160600851827.

Cicerone, R.D., Ebel J.E., and Britton J. (2009). A systematic compilation of earthquake precursors, Tectonophysics 476, 371-396. doi:10.1016/j.tecto.2009.06.008.

Cornell ,C.A. (1968). Engineering seismic risk analysis, Bull. Seismol .Soc. Am., 58:1583-1606.

Corrado, R., Caputo R., Filizzola C,. Pergola N., Pietrapertosa C., and Tramutoli V. (2005). Seismically active area monitoring by robust TIR satellite techniques: a sensitivity analysis on low magnitude earthquakes in Greece and Turkey, Nat. Hazards Earth Syst. Sci., 5, 101-108.

Cuomo, V., Filizzola C., Pergola N., Pietrapertosa C., and Tramutoli V. (2004). A self-sufficient approach for GERB cloudy radiance detection, Atmos. Res., 72, 39-56.

Di Bello, G., Filizzola C., Lacava T., Marchese F., Pergola N., Pietrapertosa C., Piscitelli S., Scaffidi I., and Tramutoli V. (2004) Robust Satellite Techniques for Volcanic and Seismic Hazards Monitoring, Ann. Geophys., 47, 49-64.

Dziewonski, A.M., Chou T.A., and Woodhouse J.H. (1981). Determination of earthquake source parameters from waveform data for studies of global and regional seismicity, J. Geophys. Res., 86, 2825-2852. doi:10.1029/J086iB04p02825.

Dobrovolsky, I.P., Zubkov S.I., and Miachkin V.I. (1979). Estimation of the size of earthquake preparation zones, Pure Appl. Geophys., 117, 1025-1044. doi:10.1007/BF00876083.

Ekström, G., Nettles M., and Dziewonski A.M. (2012). The global CMT project 2004-2010: Centroid-moment tensors for 13,017 earthquakes, Phys. Earth Planet. Inter., 200-201, 1-9. doi:10.1016/j.pepi.2012.04.002.

Eleftheriou, A., Filizzola C., Genzano N., Lacava T., Lisi M., Paciello R., Pergola N,. Vallianatos F., and Tramutoli V. (2016). Long-Term RST Analysis of Anomalous TIR Sequences in Relation with Earthquakes Occurred in Greece in the Period 2004-2013, Pure Appl. Geophysics, 173(1), 285-303. http://doi.org/10.1007/s00024-015-1116-8.

EMSEV, 2018 website (2018). Electro-Magnetic Studies of Earthquakes and Volcanoes - Integrating Geophysical Observations from Ground to Space for Earthquake and Volcano Investigations, http://web.unibas.it/emsev2018/index.php/en/, last access: 22/01/2019.

Eneva, M., Adams D., Wechsler N., Ben-Zion Y., and Dor O. (2008). THERMAL PROPERTIES OF FAULTS IN SOUTHERN CALIFORNIA FROM REMOTE SENSING DATA. 71.

Filizzola, C., Pergola N., Pietrapertosa C., and Tramutoli V. (2004). Robust satellite techniques for seismically active areas monitoring: a sensitivity analysis on September 7, 1999 Athens's earthquake, Phys. Chem. Earth 29, 517-527. doi:10.1016/j.pce.2003.11.019.

Freund, F.T. (2007a). Pre-earthquake signals - Part I: Deviatoric stresses turn rocks into a source of electric currents, Nat. Hazards Earth Syst. Sci., 7, 535-541.

Freund, F.T (2007b). Pre-earthquake signals - Part II: Flow of battery currents in the crust, Nat. Hazards Earth Syst. Sci., 7, pp. 1-6.

Freund, F. T., Takeuchi A. and Lau B. W. S. (2006). Electric currents streaming out of stressed igneous rocks - A step towards understanding pre-earthquake low frequency EM emissions, Phys. Chem. Earth, Parts A/B/C, 2006, 31, pp. 389-396.

Freund, F.T., Takeuchi A., Lau B.W.S., Al-Manaseer A., Fu C.C., Bryant N., and Ouzounov D. (2007). Stimulated infrared emission from rocks: assessing a stress indicator, eEarth, 2, pp. 1-10.

Geller R.J. (2011) Shake-up time for Japanese seismology, Nature 472:407-409. doi:10.1038/nature10105.

Genzano, N., Aliano C., Filizzola C., Pergola N., and Tramutoli V. (2007). Robust satellite technique for monitoring seismically active areas: The case of Bhuj-Gujarat earthquake, Tectonophysics 431, 197-210.

Genzano, N., Aliano C., Corrado R., Filizzola C., Lisi M., Mazzeo G., Paciello R., Pergola N., and Tramutoli V. (2009a). RST analysis of MSG-SEVIRI TIR radiances at the time of the Abruzzo 6 April 2009 earthquake, Nat. Hazards Earth Syst. Sci. 9, 2073-2084.

Genzano, N., Aliano C., Corrado R., Filizzola C., Lisi M., Paciello R., Pergola N., Tsamalashvili T., and Tramutoli V. (2009b). 
Assessing of the robust satellite techniques (RST) in areas with moderate seismicity, Proc. Multitemp 2009. Mistic, Connecticut, USA, 28-30 July 2009, 307-314.

Genzano, N., Filizzola C., Paciello R. Pergola N., and Tramutoli V. (2015). Robust Satellite Techniques (RST) for monitoring Earthquake prone areas by satellite TIR observations: the case of 1999 Chi-Chi earthquake (Taiwan), J. Asian Earth Sci., 114, 289-298. http://doi.org/10.1016/j.jseaes.2015.02.010.

Gorny, V.I., Salman A.G. Tronin A.A., and Shilin B.B. (1988) The Earth outgoing IR radiation as an indicator of seismic activity, Proceeding Acad. Sci. USSR 301, 67-69.

Halle, W., Oertel D. Schlotzhauer G., and Zhukov B. (2008). Early warning of earthquakes by space-borne infrared sensors, Erdbebenfrüherkennung mit InfraRot Sensoren aus dem Weltraum, 1-106.

Han, P., Hattori K., Hirokawa M., Zhuang J., Chen C.H., Febriani F., Yamaguchi H., Yoshino C., Liu J.Y., and Yoshida S. (2014). Statistical analysis of ULF seismomagnetic phenomena at Kakioka, Japan, during 2001-2010, J. Geophys. Res.: Space Physics, 119(6), 4998-5011. http://doi.org/10.1002/2014JA019789.

Huang, Q.H. (2011b). Rethinking earthquake-related DC-ULF electromagnetic phenomena: towards a physics-based approach, Nat. Hazards Earth. Syst. Sci., 11(11), 2941-2949, doi:10.5194/nhess-11-2941-2011.

ISIDe working group (2016) version 1.0, DOI:10.13127/ISIDe.

Jiao, Z.H., Zhao J.,and Shan X. (2018). Pre-seismic anomalies from optical satellite observations: a review, Nat. Hazards Earth. Syst. Sci., 18, 1013-1036 https://doi.org/10.5194/nhess-18-1013-2018.

Kagan, Y.Y. and Jackson D.D. (2013).Tohoku earthquake: a surprise ?, Bull. Seismol. Soc. Am., 103, 1181-1194.

Khalili M, Panah SKA, Eskandar SSA (2019). Using Robust Satellite Technique (RST) to determine thermal anomalies before a strong earthquake: A case study of the Saravan earthquake (April 16th, 2013, MW=7.8, Iran), JJ. Asian Earth Sci., 173, 70-78. http://doi.org/10.1016/j.jseaes.2019.01.009.

Kossobokov, V.G. (2006). Testing earthquake prediction methods: «The West Pacific short-term forecast of earthquakes with magnitude MwHRV = 5.8», Tectonophysics 413, 25-31.

Kossobokov, V., and Nekrasova A. (2012). Global seismic hazard assessment program (GSHAP) maps are Erroneous, Seismic Instruments 48(2), 162-170.

Li, M. and Parrot M. (2013). Statistical analysis of an ionospheric parameter as a base for earthquake prediction, J. Geophys. Res.: Space Physics 118, 3731-3739. doi:10.1002/jgra.50313.

Lisi, M., Filizzola C., Genzano N., Grimaldi C.S.L,. Lacava T., Marchese F., Mazzeo G., Pergola N., and Tramutoli V. (2010). A study on the Abruzzo 6 April 2009 earthquake by applying the RST approach to 15 years of AVHRR TIR observations, Nat. Hazards Earth Syst. Sci. 10, 395-406. doi:10.5194/nhess-10-395-2010.

Lisi, M., Filizzola C., Genzano N., Paciello R., Pergola N., and Tramutoli V. (2015). Reducing atmospheric noise in RST analysis of TIR satellite radiances for earthquakes prone areas satellite monitoring, Phys. Chem. Earth, Parts A/B/C, 85-86, 87-97. http://doi.org/10.1016/j.pce.2015.07.013

Liu, J.Y., Chen Y.I., Chuo Y.J., and Chen C.S. (2006). A statistical investigation of preearthquake ionospheric anomaly, J. Geophys. Res. 111, A05304. doi:10.1029/2005JA011333.

Ma, J., Chen S., Hu X., Liu P., and Liu L. (2010). Spatial-temporal variation of the land surface temperature field and present-day tectonic activity, Geosci. Front., 1, 57-67, doi:10.1016/j.gsf.2010.09.002.

Meletti, C., Galadini F., Valensise G., Stucchi M., Basili R., Barba S., Vannucchi G., and Boschi E. (2008). A seismic source zone model for the seismic hazard assessment of the Italian territory, Tectonophysics, 450(1-4), 85-108, doi:10.1016/j.tecto.2008.01.003.

Molchan, G.M. (1990). Strategies in strong earthquake prediction, Phys. Earth Planet. Inter., 61 , 84-98.

Molchan, G.M. (1991). Structure of optimal strategies in earthquake prediction, Tectonophysics 193:267-276. doi:10.1016/0040-1951(91)90336-Q.

Molchan, G.M. (1997). Earthquake prediction as a decision-making problem, Pure Appl. Geophys., 149, 233-247. doi:10.1007/BF00945169.

Molchan, G.M., Kagan Y.Y. (1992). Earthquake prediction and its optimization. J. Geophys. Res., 97, 4823. doi:10.1029/91JB03095.

Mulargia, F., Stark F.B., and Geller R.J.(2017). Why is Probabilistic Seismic Hazard Analysis (PSHA) still used?, Phys. Earth Planet. Int., 264, 63-75.

Okyay, Ü. (2012). Evaluation of thermal remote sensing for detection of thermal anomalies as earthquake precursors. A Case Study for Malatya-Pütürge-Doğanyol (Turkey) Earthquake, July 13, 2003, Masters program in Geospatial Technologies. 


\section{Nicola Genzano et al.}

Ouzounov, D., and Freund F. (2004). Mid-infrared emission prior to strong earthquakes analyzed by remote sensing data, Adv. Space Res., 33, 268-273. doi:10.1016/S0273-1177(03)00486-1.

Piroddi, L.,and Ranieri G. (2012). Night thermal gradient: A New potential tool for earthquake precursors studies. An application to the seismic area of L'Aquila (central Italy), IEEE Journal of Selected Topics in Appli. Earth Ob. Remote Sens., 5(1), 307-312. http://doi.org/10.1109/JSTARS.2011.2177962.

Pergola, N., Aliano C., Coviello I., Filizzola C., Genzano N., Lacava T., Lisi M., Mazzeo G., and Tramutoli V. (2010) Using RST approach and EOS-MODIS radiances for monitoring seismically active regions: a study on the 6 April 2009 Abruzzo earthquake, Nat Hazards Earth Syst Sci 10, 239-249. doi:10.5194/nhess-10-239-2010.

Pondrelli, S., Morelli A., Ekström G., Mazza S., Boschi E., and Dziewonski A.M. (2002). European-Mediterranean regional centroid-moment tensors: 1997-2000, Phys. Earth Planet. Int., 130, 71-101, 2002.

Pondrelli, S., Salimbeni S.,Ekström G., Morelli A., Gasperini P., Vannucci G. (2006). The Italian CMT dataset from 1977 to the present, Phys. Earth Planet. Int., 286-303, doi:10.1016/j.pepi.2006.07.008,159/3-4.

Pre-earthquakes project website (2019). Processing Russian and European EARTH observations for earthQUAKE precursors Studies, http://www.pre-earthquakes.org/, last access: 22/01/2019.

Pulinets, S.A. (2004). Ionospheric precursors of earthquakes; recent advances in theory and practical applications, Terr., Atm. Ocean Sci. 15, 413-435.

Pulinets, S.A. (2006). Space technologies for short-term earthquake warning, Advances in Space Research 37, 643-652.

Pulinets, S.A., and Boyarchuk K.A. (2004). Ionospheric Precursors of Earthquakes. Berlin, German: Springer.

Pulinets, S.A., Ouzounov D. (2011). Lithosphere-Atmosphere-Ionosphere Coupling (LAIC) model - An unified concept for earthquake precursors validation, J. Asian Earth Sci. 41, 371-382.

Qiang, Z.-J., and Dian C.-G. (1992). Satellite thermal infrared impending temperature increase precursor of Gonghe earthquake of magnitude 7.0, Qinghai province, Geosci., 6, 297-300.

Qiang, Z.J., Xu X.D., and Dian C.G. (1991). Thermal infrared anomaly precursor of impending earthquakes, Chinese Sci Bull 36, 319-323.

Qiang, Z., Xu X., and Dian C., (1997). Case 27 thermal infrared anomaly precursor of impending earthquakes, Pure Appl. Geophys., 149, 159-171, doi:10.1007/BF00945166.

Scholz, C.H., Sykes L.R., and Aggarwal Y.P. (1973) Earthquake prediction: a physical basis, Science 181(4102), 803-810. doi:10.1126/science.181.4102.803.

Stein,S.A., Geller R.J. and Liu M.C. (2012). Why earthquake hazard maps often fail and what to do about it (Review),Tectonophys., 562-563, 1-25.

Tramutoli, V. (1998). Robust AVHRR Techniques (RAT) for Environmental Monitoring: theory and applicationsm In: Zilioli E (ed) Proc. SPIE. 101-113.

Tramutoli, V., (2005). Robust Satellite Techniques (RST) for natural and environmental hazards monitoring and mitigation: ten year of successful applications, In: Liang S, Liu J, Li X, Liu R, Schaepman M (eds) 9th Int. Symp. Phys. Meas. Signatures Remote Sensing, IGSNRR, Beijing, China , XXXVI, 792-795.

Tramutoli ,V. (2007), Robust Satellite Techniques (RST) for Natural and Environmental Hazards Monitoring and Mitigation: Theory and Applications, Int. Work. Anal. Multi-temporal Remote Sens. Images. IEEE, 1-6.

Tramutoli, V., Di Bello G., Pergola N., and Piscitelli S. (2001.) Robust satellite techniques for remote sensing of seismically active areas, Ann di Geofis 44, 295-312.

Tramutoli, V., Cuomo V., Filizzola C., Pergola N., Pietrapertosa C. (2005). Assessing the potential of thermal infrared satellite surveys for monitoring seismically active areas: The case of Kocaeli (İzmit) earthquake, August 17, 1999, Remote Sens Environ. 96, 409-426. doi:10.1016/j.rse.2005.04.006.

Tramutoli, V., Aliano C., Corrado R., Filizzola C., Genzano N., Lisi M., Lanorte V., Tsamalashvili T .(2009). Abrupt change in greenhouse gases emission rate as a possible genetic model of TIR anomalies observed from satellite in Earthquake active regions. Proc. ISRSE 2009, 567-570.

Tramutoli, V., Aliano C., Corrado R., Filizzola C., Genzano N., Lisi M., Martinelli G., and Pergola N. (2013). On the possible origin of thermal infrared radiation (TIR) anomalies in earthquake-prone areas observed using robust satellite techniques (RST), Chem Geol 339, 157-168. doi:10.1016/j.chemgeo.2012.10.042.

Tramutoli, V., Jakowski N., Pulinets S., Romanov A., Filizzola C., Shagimuratov I., Pergola N., Ouzounov D., Papadopulos G., Genzano N., Lisi M., Alparslan E., Wilken V., Romanov A., Zakharenkova I., Paciello R., Coviello I., Romano G., Tsybulia K., Inan S., and Parrot M. (2014). From PRE-EARTQUAKES to EQUOS: how to exploit multi-parametric observations within a novel system for time-dependent assessment of seismic hazard (T-DASH) in a pre- 
operational Civil Protection context, Prooceding of Second European Conference on Earthquake Engineering and Seismology (2ECEES) Turkey 24-29 August, 2014.

Tramutoli, V., Corrado R., Filizzola C., Genzano N., Lisi M., Pergola N. (2015a). From visual comparison to Robust Satellite Techniques: 30 years of thermal infrared satellite data analyses for the study of earthquakes preparation phases, Bollettino Di Geofisica Teorica Ed Applicata, 56(June), 167-202. http://doi.org/10.4430/bgta0149.

Tramutoli, V., Corrado R., Filizzola C., Genzano N., Lisi M., Paciello R., Pergola N. (2015b). One year of RST based satellite thermal monitoring over two Italian seismic areas, Bollettino Di Geofisica Teorica Ed Applicata, 56(June), 275-294. http://doi.org/10.4430/bgta0150.

Tramutoli, V., Filizzola C., GenzanoN., Lisi M. (2018a). Robust Satellite Techniques for detecting pre-seismic thermal anomalies, In D. Ouzounov, S. Pulinets, K. Hattori, \& P. Taylor (Eds.), Pre-Earthquake Processes: A Multidisciplinary Approach to Earthquake Prediction Studies, AGU publications, Geophysical Monograph Series, 234-258.

Tramutoli, V., Genzano N., Lisi M., Pergola N. (2018b). Significant cases of pre-seismic TIR anomalies. Pre-Earthquake Processes: A Multidisciplinary Approach to Earthquake Prediction Studies, AGU publications, Geophysical Monograph Series, 331-338.

Tronin, A.A .(1996). Satellite thermal survey-a new tool for the study of seismoactive regions, Int. J. Remote Sens., 17,1439-1455. doi:10.1080/01431169608948716.

Tronin, A.A. (2006). Remote sensing and earthquakes: A review, Phys. Chem. Earth. 31, 138-142. doi:10.1016/j.pce.2006.02.024.

Tronin, A.A., Hayakawa M, and Molchanov O.A.(2002). Thermal IR satellite data application for earthquake research in Japan and China, J. Geodyn., 33, 519-534, doi:10.1016/S0264-3707(02)00013-3.

Tsai, Y.-B., Liu J.-Y.., Ma K.-F., Yen H.-Y., Chen K.-S., Chen Y.-I., and Lee C-.P. (2006). Precursory phenomena associated with the 1999 Chi-Chi earthquake in Taiwan as identified under the iSTEP program, Phys. Chem. Earth, Parts A/B/C 31, 365-377. doi:10.1016/j.pce.2006.02.035.

Wu, L.X.,and Liu S.J. (2009). Remote Sensing Rock Mechanics and Earthquake Infrared Anomalies. Edited by: Jedlovec G., in: Adv.Geosci. Remote Sens, Sweden In-Teh., 709-741.

Wu, L.X,. Qin K., and Liu S.J. (2012). GEOSS-based thermal parameters analysis for earthquake anomaly recognition. In Proceedings of the IEEE, 99, 1-17; doi:10.1109/JPROC. 2012.2184789.

Xie, T., Kang C.L., Ma W.Y. (2013). Thermal infrared brightness temperature anomalies associated with the Yushu (China) Ms $=7.1$ earthquake on 14 April 2010, Nat. Hazards. Earth Syst. Sci., 13(4), 1105-1111. http://doi.org/10.5194/nhess-13-1105-2013.

Xiong, P., Gu X.F., Bi Y.X,. Shen X.H., Meng Q.Y., Zhao L.M., Zhao L.M., Kang C.L., Chen L.Z., Jing F., Yao N., Zhao Y.H., Li X.M., Li Y., and Dong J.T. (2013). Detecting seismic IR anomalies in bi-angular Advanced Along-Track Scanning Radiometer data, 13(8), 2065-2074. http://doi.org/10.5194/nhess-13-2065-2013

Xu, X., Xu X., and Wang Y. (2000). Satellite infrared anomaly before the Nantou Ms= 7.6 earthquake in Taiwan, China. Acta Seismologica Sinica, 13(6), 710-713.

Yang, Y., and Guo G. (2010). Studying the thermal anomaly before the Zhangbei earthquake with MTSAT and meteorological data. Int.1 J. Remote Sens. Appl., 31(11),2783-2791. http://doi.org/10.1080/01431160903095478.

Yasuoka, Y., Igarashi G., Ishikawa T., Tokonami S., and Shinogi M. (2006). Evidence of precursor phenomena in the Kobe earthquake obtained from atmospheric radon concentration. Appl. Geochemistry, 21, 1064-1072.

Zhang, Y.S., Guo X., Zhong M.J., Shen W.R., Li W., and He B. (2010). Wenchuan earthquake: Brightness temperature changes from satellite infrared information. Chinese Science Bulletin, 55(18), 1917-1924. http://doi.org/10.1007/s11434-010-3016-8.

*CORRESPONDING AUTHOR: Nicola GENZANO,

School of Engineering, University of Basilicata,

Potenza, Italy;

e-mail:nicola.genzano@unibas.it

(c) 2020 the Istituto Nazionale di Geofisica e Vulcanologia.

All rights reserved 